\title{
SAPHO: has the time come for tailored therapy?
}

\section{Adelaide Sofia Batalha Figueiredo ${ }^{1,2}$ (1) Ana Luísa Oliveira ${ }^{1,3} \cdot$ António Caetano $^{4} \cdot$ Maria Francisca Moraes-Fontes $^{1}$}

Received: 22 May 2019 / Revised: 26 June 2019 / Accepted: 1 July 2019 / Published online: 16 July 2019

(C) International League of Associations for Rheumatology (ILAR) 2019

\begin{abstract}
SAPHO (synovitis, acne, pustulosis, hyperostosis and osteitis) syndrome is a heterogeneous condition combining osteoarticular and cutaneous manifestations. Conventional treatments are mostly ineffective. We hereby report two patients, the first with an aggressive form of disease and the second with an incomplete response to two different anti-TNF- $\alpha$ agents. Both were successfully treated with tocilizumab and ustekinumab, respectively, over a long period of time. A narrative review of a biological therapy in SAPHO syndrome yielded very little information on the specific use of these agents. We highlight the advantages of personalising therapy and describe emerging promising treatments for this disease.
\end{abstract}

Keywords Anti-IL-1 agents · Anti-IL-12/IL-23 agents · Anti-IL-6 agents · Anti-TNF- $\alpha$ agents · SAPHO syndrome · Treatment

\section{Introduction}

Synovitis, acne, pustulosis, hyperostosis and osteitis (SAPHO) syndrome is a rare chronic immune-mediated condition characterised by combined osteoarticular and cutaneous manifestations [1]. Not every patient presents with the full spectrum of the disease [2]. Given its heterogeneity, diagnosis is challenging and conventional treatments, ranging from nonsteroidal anti-inflammatory drugs (NSAIDs), corticosteroids, antibiotics and bisphosphonates to several disease-modifying anti-rheumatic drugs (DMARDs) such as methotrexate, sulfasalazine or azathioprine, have yielded suboptimal responses [3,4]. Anti-tumour necrosis factor-alpha (antiTNF- $\alpha$ ) agents and interleukin-1 (IL-1) antagonists have achieved more effective outcomes but some patients remain refractory and may only respond in a single organ domain $[4$,

Adelaide Sofia Batalha Figueiredo

adelaide.sofia.figueiredo@gmail.com

1 Unidade de Doenças Auto-imunes/Serviço Medicina 7.2, Hospital de Curry Cabral, Centro Hospitalar Universitário de Lisboa Central, Lisbon, Portugal

2 Serviço de Medicina IV, Hospital de Santarém EPE, Av. Bernardo Santareno, 2005-177 Santarém, Portugal

3 Serviço de Medicina I, Unidade Local de Saúde do Baixo Alentejo, Hospital José Joaquim Fernandes, Beja, Portugal

4 Serviço de Radiologia do Hospital de Curry Cabral, Centro Hospitalar Universitário de Lisboa Central, Lisbon, Portugal
5]. There is scarce information on the value of more recent biological response modifier therapies.

We first describe the follow-up of two patients with SAPHO syndrome treated with tocilizumab and ustekinumab, respectively. We then review all previous studies involving patients with SAPHO treated with biological agents, synthetic agents and cell signalling pathway inhibitors, with a special focus on non-anti-TNF- $\alpha$ agents, with respect to therapeutic outcome. We suggest the current array of biological therapies allows for the treatment of SAPHO patients in a personalised fashion, aiming to achieve early remission and preventing irreversible organ damage.

\section{Methods}

Demographic data, clinical records, therapeutic options and outcomes in patients treated with biological agents were the focus of the case reports and literature review. The latter was performed in a narrative form, through a PubMed search, using the terms "SAPHO" and "syndrome" and "treatment", up until the 31st December 2018, with no other publication date constraints. Additional relevant literature was hand-picked. The search was performed by two authors and resulted in a total of 324 articles. The first selection was restricted to manuscripts written in English, French, Spanish and Portuguese but only manuscripts written in English were found. Patient reports in review articles were included but we rejected editorials, commentaries, congress presentations and articles reporting SAPHO patients not exposed to biological therapies. 
Then, chronologically, we selected every single publication reporting clinical cases that described SAPHO syndrome patients subjected to biologicals and more recent compounds, obtaining a total of 40 manuscripts (11 single-centre cohort and 29 single case reports) as illustrated in the flowchart (Fig. 1). Mendeley was used as the reference manager. Duplicate information regarding individual patients was resolved. While the present study was being conducted, a series of 45 SAPHO patients subjected to biological therapy was published [6]. We found 22 additional cases and separately analysed biological non-TNF- $\alpha$ therapy-treated patients, the latter constituting our main research focus.

There is no unified concept of remission in SAPHO syndrome. When all organ systems ameliorate, response is generally considered complete. When response to therapy is dichotomized into cutaneous or articular, it is considered partial, according to symptomatic relief and irrespective of organ damage.

\section{Results}

\section{Patient 1 case report}

In 2001, a 27-year-old male, HLA B27 negative, complained of severe sternoclavicular and left arm pain for several years. Imaging showed bilateral clavicular and left humerus osteosclerosis and hyperostosis; concordantly, bone scintigraphy revealed increased uptake in both first sternocostal and sternoclavicular joints and middle third of the humeral shaft. Of note, the patient had suffered from severe acne vulgaris (face and trunk) from the age of 15 , treated intermittently with doxycycline and isotretinoin with resolution of cutaneous manifestations. Combined NSAIDs, calcium supplementation, alendronate, weekly methotrexate (MTX), up to $25 \mathrm{mg}$ per week, and prednisolone (10 mg per day) failed to provide pain relief, preventing him from working for a period of approximately 5 years. A regimen of intravenous tocilizumab (TCZ), $8 \mathrm{mg} / \mathrm{kg}$ per month, was attempted in 2011 and resulted in complete clinical remission for the next 8 years, up to the present time. Follow-up bone scintigraphy (2018) showed improvement (Fig. 2). Despite erosive changes (Fig. 3), the patient has been pain free and able to cope with a full-time employment since TCZ onset. He refused switching to subcutaneous formulation of TCZ and continues monthly therapy.

\section{Patient 2 case report}

In 2000, a 41-year-old female, HLA B27 negative, presented with severe sternoclavicular joint synovitis. She suffered from palmoplantar pustulosis for the past 15 years which worsened during the previous year with polyarthralgia of the wrists, elbows, shoulders and proximal interphalangeal, metacarpophalangeal and tibiotarsal joints. She started NSAID and weekly MTX up to $20 \mathrm{mg}$ per week, with mild clinical improvement of the peripheral joints but no improvement regarding skin manifestations and anterior chest pain. Bone scintigraphy showed in-

Fig. 1 Literature review methodology flowchart

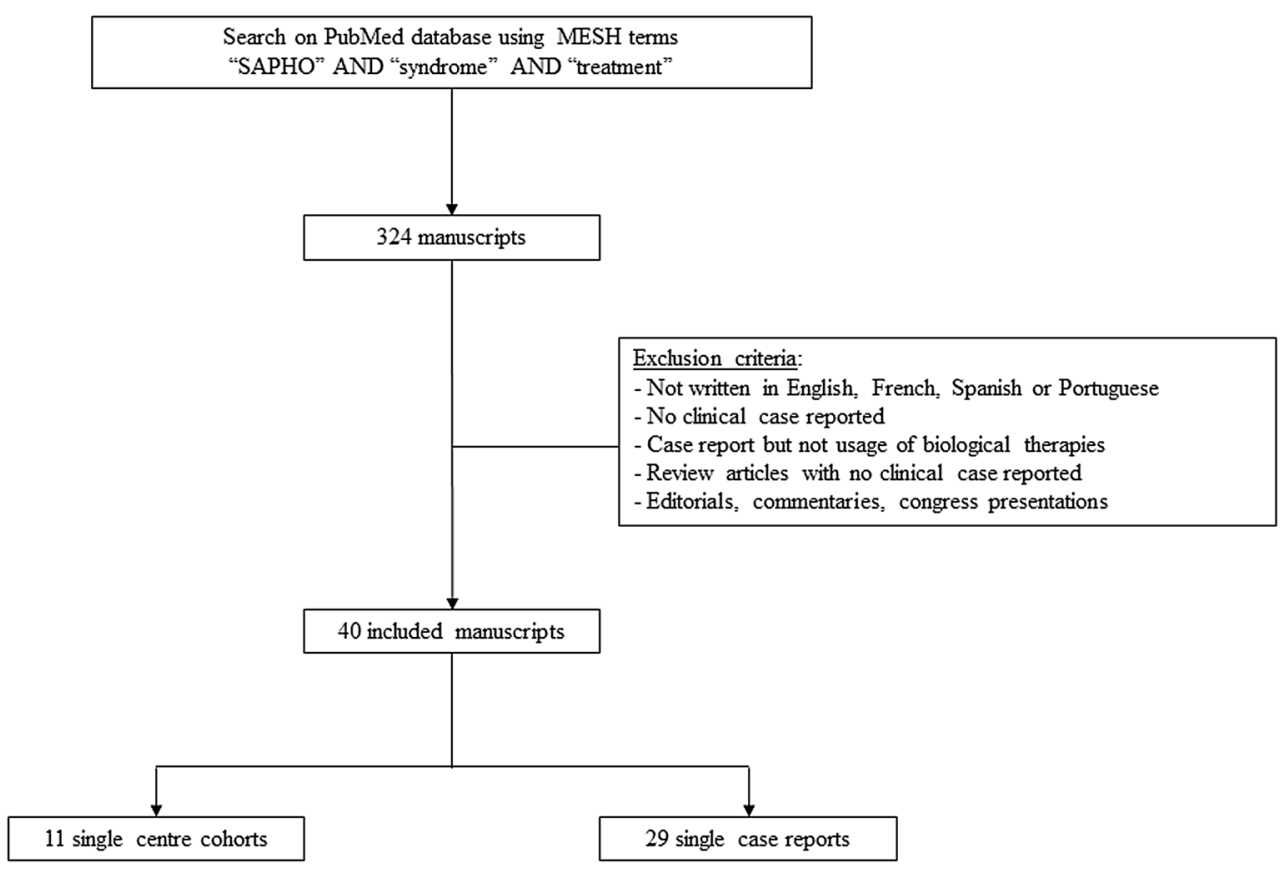


Fig. 2 Sequential bone scintigraphy: Initial bone scintigraphy images were obtained $2 \mathrm{~h}$ after radiolabelled injection. There is increased uptake in the middle third of the humeral shaft, sternocostal and sternoclavicular joints, with much less intensity at follow-up. $\mathrm{L}=$ left; $\mathrm{R}=$ right

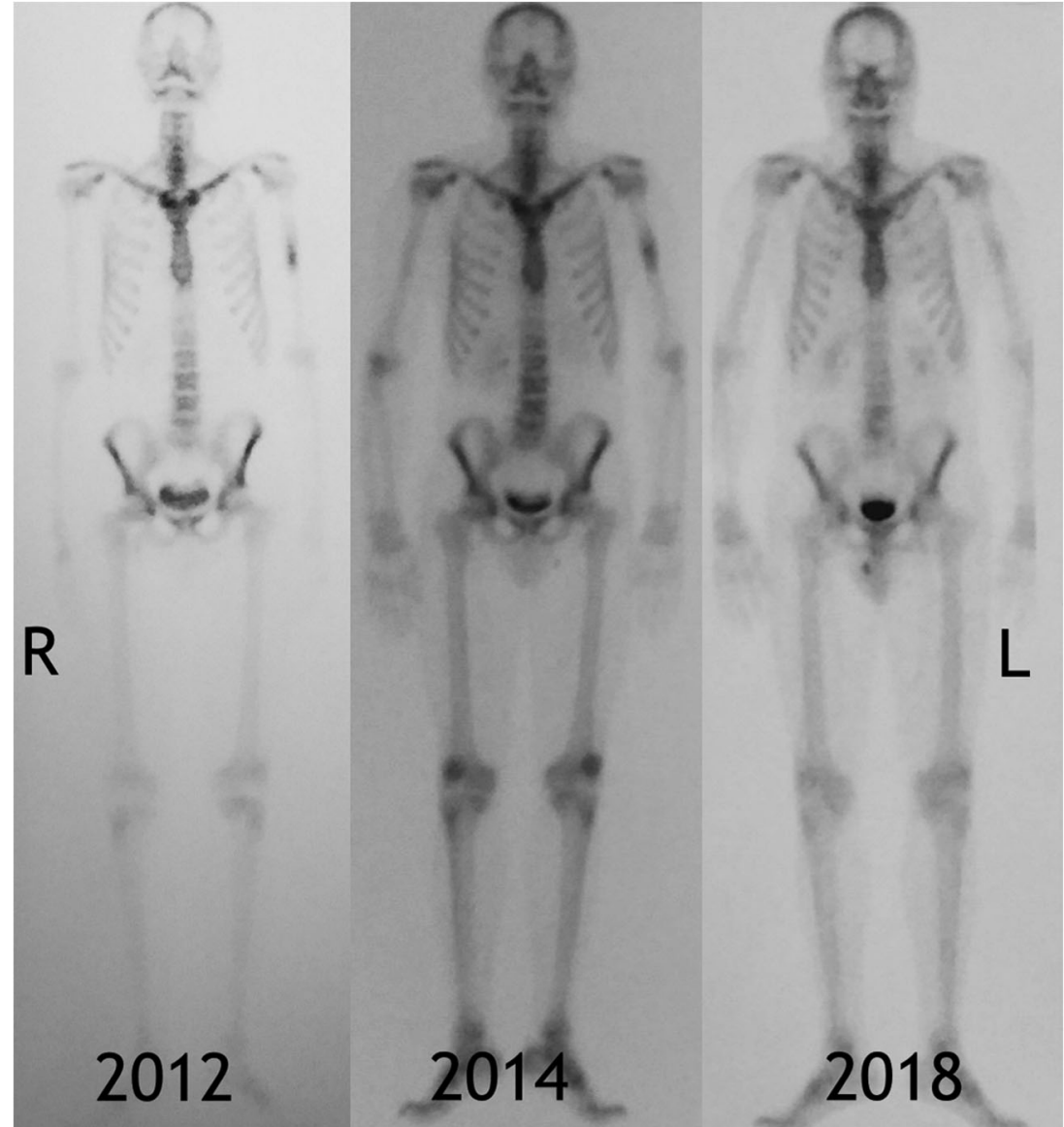

creased uptake on both sternoclavicular joints, first right rib and first left sternocostal joint. In December 2011, a regimen of adalimumab $40 \mathrm{mg}$ every 2 weeks in addition to MTX was prescribed and provided symptomatic relief. However, the treatment had to be interrupted after 2 months due to new onset scalp psoriasis with severe alopecia.
Fig. 3 Computerised tomography multiplanar reconstruction at the shoulder girdle level. Paracoronal views show sternoclavicular (a) and costoclavicular (b) joint erosion with marginal osteophytosis on the clavicle side, accompanied by joint space narrowing; para-axial views reveal diffuse

osteosclerosis and mild hyperostosis affecting the middle third of both clavicles, more pronounced on the left (c). $\mathrm{L}=$ left; $\mathrm{R}=$ right

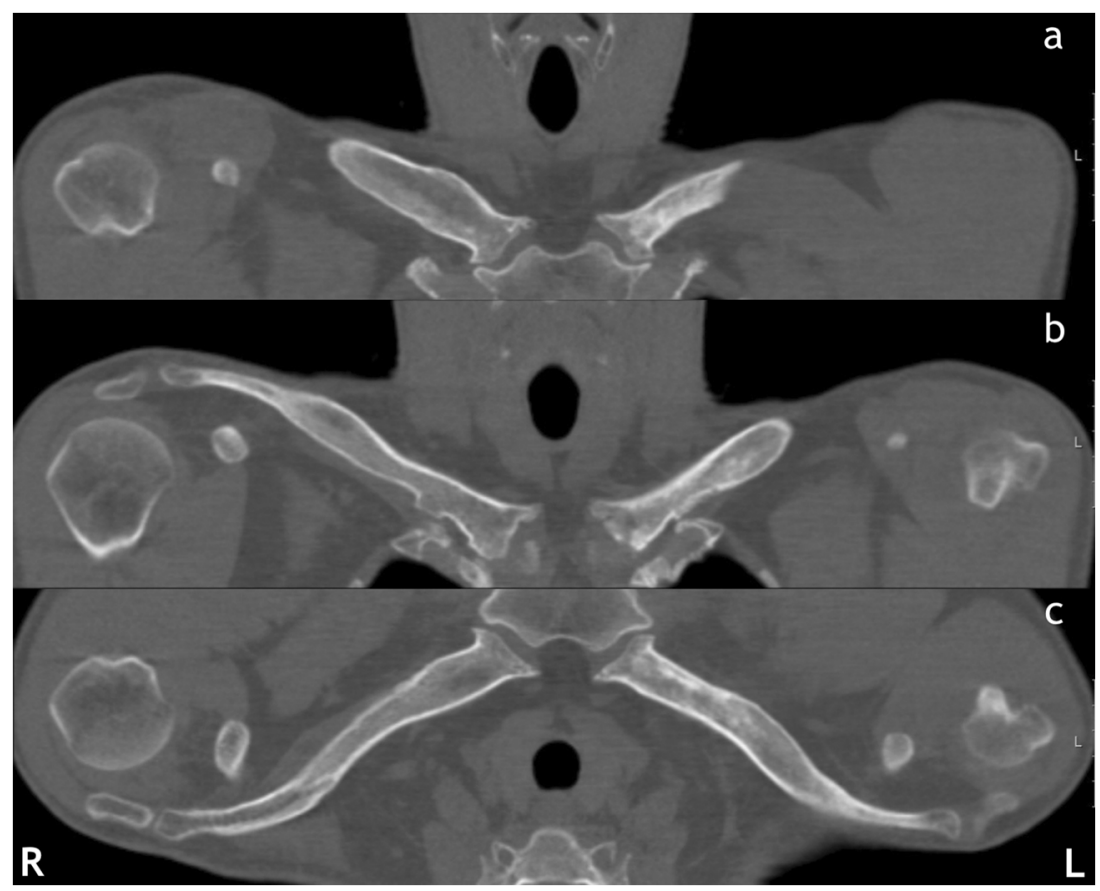


Treatment was switched from May 2012 to etanercept $50 \mathrm{mg}$ per week, providing intermittent improvement of joint pain but failure to resolve palmoplantar pustulosis. A switch to ustekinumab was made in March 2016, resulting in symptomatic sustained cutaneous and articular disease complete remission with discontinuation of MTX over the next 3 years (Figs. 4 and 5).

Elevated serum markers of inflammation (C-reactive protein and ESR) normalised in both patients. Neither patient experienced side effects.

\section{Literature review}

Our literature review found a total of 67 patients treated with biological therapies. We selected eight manuscripts which described a total of 19 case reports of SAPHO syndrome for which non-TNF- $\alpha$ and recently developed agents including targeted synthetic DMARDs were used. Data extraction concerning every single patient found in the literature was exhaustively documented according to a pre-defined protocol. As outlined in Table 1, most patients reported were female $(N=14 ; 74 \%)$ with a mean age similar between females and males $(43.2 \pm 11$ and $43.2 \pm 14$, respectively). Except for 2 patients (\#15 and \#16), osteoarticular and cutaneous manifestations occurred in every patient, 15 of whom presented with palmoplantar pustulosis. Overall, anakinra, ustekinumab, secukinumab and tocilizumab were successful in patients who were refractory to prior NSAID, corticosteroid, conventional DMARDs (cDMARDs), pamidronate and anti-TNF- $\alpha$ therapy. Of note, patients \#12 and \#14 failed to respond to two classes of biological DMARDs (bDMARDs); patient \#17 was refractory to three different classes of bDMARDs and was rescued by apremilast; tofacitinib was also successful in a single patient (\#18). Mean time from diagnosis to final treatment was only reported for 13 patients and was highly variable ( $8 \pm 6$ years).
After a mean follow-up of $8 \pm 6$ months, only four patients had failed to achieve clinical remission (\#7, 9, 10, 14).

We pooled all patients that ever switched to a second biological therapy $(n=18)$, consisting of those that switched between anti-TNF- $\alpha$ drugs $(n=5)$ and another group that switched to a different class of biological agent $(n=13,12$ taken from Table 1). Full remission was described in $72 \%(n=13 / 18)$, three patients failing to respond and two patients only achieving partial remission. Of note, novel or aggravating cutaneous reactions occurred in 8 patients $(44 \%)$ and these were described with every class of bDMARD (Table 2). Paradoxical psoriasis reactions were observed in 2 patients (one under ustekinumab and another under secukinumab-\#9 and 14). A third patient had a local reaction after an etanercept injection and a pustular skin rash consistent with a drug hypersensitivity reaction during secukinumab treatment. Four patients under infliximab treatment had cutaneous reactions namely a skin flare, allergic urticaria, a psoriatic rash and worsening of palmoplantar pustulosis lesions that resolved after treatment discontinuation. A single patient developed an aseptic abscess during tocilizumab treatment remaining unclear whether this was an adverse event or a complication of SAPHO syndrome.

The remaining 42 patients subjected to therapy with a single anti-TNF- $\alpha$ comprised 14 males and 28 females (Table 3). Mean age was slightly higher in females than males (42.4 \pm 12 and $35.1 \pm 11$, respectively). Mean followup was $16.8 \pm 25$ months and most patients were treated with infliximab $(n=23)$ followed by etanercept $(n=11)$, adalimumab $(n=7)$ and certolizumab pegol $(n=1)$. They had been followed for an average of 17 months, the longest having been in partial remission, on infliximab, for 11 years. Every patient had osteoarticular manifestations. Overall, complete, partial or no remissions were observed in 30,10 and 2 patients respectively. For those patients with both osteoarticular and cutaneous manifestations $(n=35)$, the

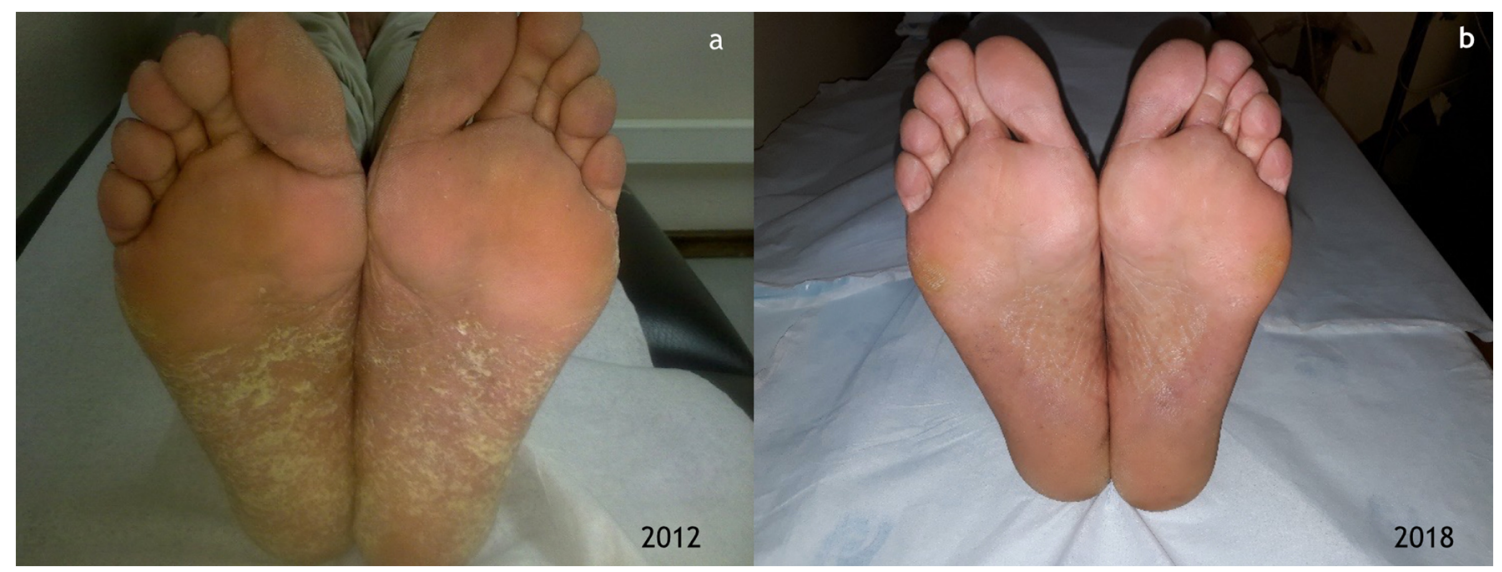

Fig. 4 Plantar pustulosis during etanercept treatment (a) and after ustekinumab (b) 


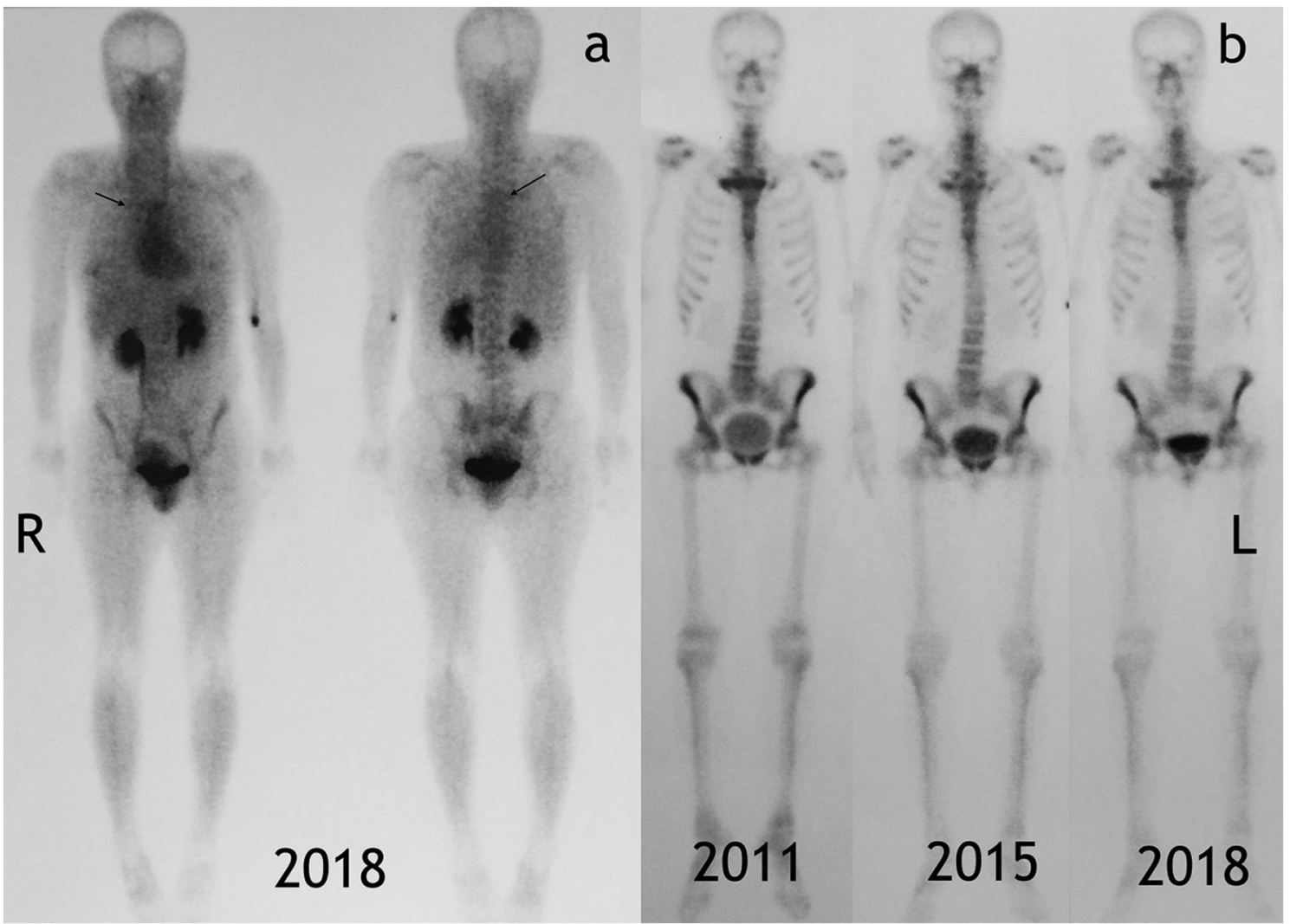

Fig. 5 Sequential bone scintigraphy: Images obtained 5 min after intravenous injection of technetium- $99 \mathrm{~m}$ demonstrates slightly increased uptake (arrow) at the sternocostal joint of the first rib on the right, anterior and posterior views (arrows) (a); $2 \mathrm{~h}$ after injection there is increased uptake at the medial surface of the first right rib, sternoclavicular joints and left sternocostal joint of the first rib with progressive reduction over an eight-year follow-up (b); $\mathrm{R}=$ right; $\mathrm{L}=$ left

Approximately half of the anti-TNF- $\alpha$-treated patients $(n=21)$ were reported between 2012 and 2015, after which time only six patients were described. Anti-IL-1 therapy was used as early as 2010 in a single patient, and in a case series of five patients in 2012 but generally overlooked thereafter. Use of other non-anti-TNF- $\alpha$ is described from 2016, underlying the younger age group of those treated with more recently marketed bDMARDs and targeted synthetic DMARDs. Lack of response to anti-TNF- $\alpha$ therapy was described with respect to SAPHO patients presenting with cutaneous manifestations, most frequently with palmoplantar pustulosis. This is in stark contrast with the overwhelming success of diverse non-anti-TNF $\alpha$ therapies, namely anakinra, ustekinumab, secukinumab, tocilizumab, tofacitinib and apremilast. While using a single database may be considered a limitation to the literature review, our strengths remain with the fact that we have undertaken the longest case-based review on SAPHO syndrome and the first focusing non-anti-TNF $\alpha$ therapies.

Our two case reports mirror the literature review with respect to a long delay from diagnosis to onset of effective therapy but highlight an important difference. The first patient had highly active osteoarticular disease and damage (erosions, 
仓

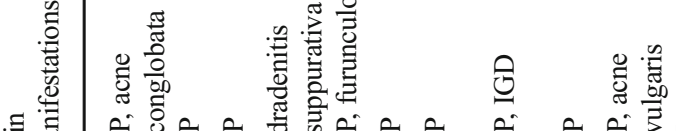

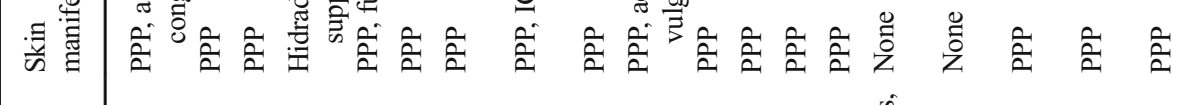

:

:

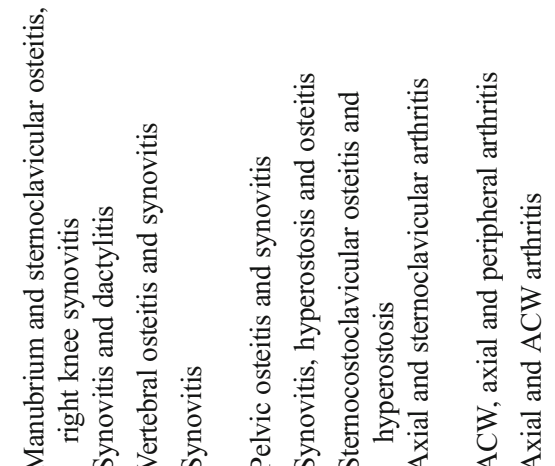

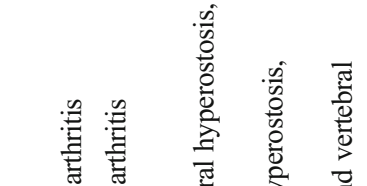

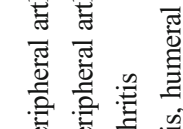

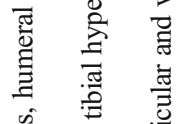

党

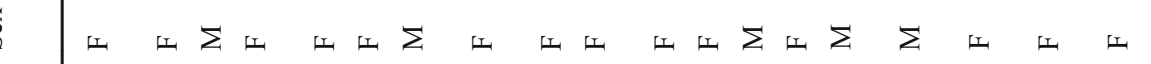

f

- $\quad$ r +

$\infty$ a으

$=\simeq$ 
Table 2 SAPHO syndrome patients subjected to switch between biological agents, describing rationale for switching and therapeutic outcomes

\begin{tabular}{|c|c|c|c|c|c|}
\hline Reference & \# in Table 1 & $\begin{array}{l}\text { Previous } \\
\text { biological agent }\end{array}$ & $\begin{array}{l}\text { Rationale for switching } \\
\text { between biologicals }\end{array}$ & Final treatment & Outcome \\
\hline \multirow[t]{3}{*}{ Wendling [8] } & 5 & INF & Lack of response & ANK & $\mathrm{CR}$ \\
\hline & 6 & INF, ETN, ADA & Lack of response & ANK & $\mathrm{CR}$ \\
\hline & 7 & ADA, ETN & Lack of response & ANK & NR \\
\hline Cornillier [9] & 8 & ETN, ADA & Lack of response & UST & $\mathrm{CR}$ \\
\hline \multirow[t]{5}{*}{ Wendling [10 } & 9 & ADA, INF & Lack of response & UST & NR \\
\hline & 10 & $\mathrm{ADA}$ & Lack of response & UST & NR \\
\hline & 12 & ADA, INF, UST & Lack of response & SEC & PR \\
\hline & 13 & INF, ADA & Lack of response & SEC & $\mathrm{CR}$ \\
\hline & 14 & INF, ANK & Lack of response & SEC & NR \\
\hline Adamo [12] & 17 & ETN, UST, ADA, SEC & $\begin{array}{l}\text { ETN-local reaction to ETN; UST-upper airway infections; } \\
\text { ADA-PPP flare; SEC-pustular skin rash }\end{array}$ & APR & $\mathrm{CR}$ \\
\hline Yang [13] & 18 & ETN & Lack of response & TFC & $\mathrm{CR}$ \\
\hline Daoussis [6] & 19 & $\mathrm{INF}, \mathrm{ADA}$ & Lack of response & SEC & $\mathrm{CR}$ \\
\hline Wagner [14] & - & $\mathrm{INF}$ & Bronchospasm & ETN & $\mathrm{CR}$ \\
\hline \multirow[t]{3}{*}{ Abdelghani [15] } & - & INF & INF-osteoarticular and skin flare & ETN & $\mathrm{CR}$ \\
\hline & - & INF & $\mathrm{INF}$-allergic urticarial reaction & $\mathrm{ADA}$ & PR \\
\hline & - & INF & $\mathrm{INF}$-psoriatic rash & ETN & $\mathrm{CR}$ \\
\hline Arias-Santiago [16] & - & INF & $\mathrm{INF}-$ worsening of skin lesions & $\mathrm{ADA}$ & $\mathrm{CR}$ \\
\hline Fujita [17] & - & $\mathrm{TCZ}$ & TCZ-aseptic abcess & INF & $\mathrm{CR}$ \\
\hline
\end{tabular}

\#, patient number; $P P P$, palmoplantar pustulosis; INF, infliximab; ETN, etanercept; ADA, adalimumab; TCZ, tocilizumab; UST, ustekinumab; SEC, seccucinumab; $A N K$, anakinra; $A P R$, apremilast; $T F C$, tofacitinib; $C R$, complete remission; $P R$, partial remission; $N R$, no remission

hyperostosis and osteitis) that severely impacted his daily activities and the disease was non-responsive to longstanding MTX. Tocilizumab was chosen on the basis of its effect on inhibition of osteoclast activity [46] and even though delayed implementation failed to prevent irreversible joint damage, therapy proved to be highly effective. Palmoplantar pustulosis, refractory to anti-TNF- $\alpha$ therapy in the second patient, was treated with ustekinumab, based on reports of its efficacy specifically regarding palmoplantar psoriasis [47] and psoriatic arthritis [48]. While we recognise that both tocilizumab and ustekinumab had become commercially available at the time treatments were started, the rationale behind their successful use must be emphasised. Both therapies were chosen to target specific clinical manifestations. Moreover, in both patients, drug survival was maintained throughout the follow-up.

Paradoxical skin lesions such as palmoplantar pustulosis may be difficult to distinguish from a psoriatic rash just as both may be due to a flare of SAPHO syndrome or induced by anti-TNF therapy [49]. Of note, in the literature review, adverse cutaneous reactions were considered to represent exacerbations or lesions of a paradoxical nature, in three and five patients, respectively. In every single case, agent discontinuation was followed by a switch to an alternative bDMARD, akin to the course of action taken when the second patient developed severe scalp psoriasis.
Until the time comes for treatment to be based on scientific judgement, our case reports and literature review suggest that, in a manner similar to the latest recommendations for systemic rheumatic and cutaneous conditions [50], patients who are unresponsive to cDMARDs should be offered early biological therapy, tailored to the prevailing clinical phenotype. Analysis of the appropriateness of therapy in SAPHO syndrome seems jeopardized owing to the absence of dedicated scores to describe global disease activity and severity of clinical osteoarticular and cutaneous manifestations. In addition, strict definitions of remission for each organ domain need to be developed. Patients with SAPHO should be carefully observed for paradoxical and adverse cutaneous events and furthermore biologicals should be switched in order to achieve the lowest possible disease activity and prevent irreversible damage. Finally, we wish to underline that SAPHO may be a severely prolonged incapacitating condition, reinforcing a recommendation to avoid therapeutic delay and highlighting the ongoing challenge of a treat to target approach. Our case reports illustrate the successful use of biological therapies chosen on the basis of specific clinical manifestations and the longest known follow-up in clinical remission for tocilizumab and ustekinumab in SAPHO syndrome. 


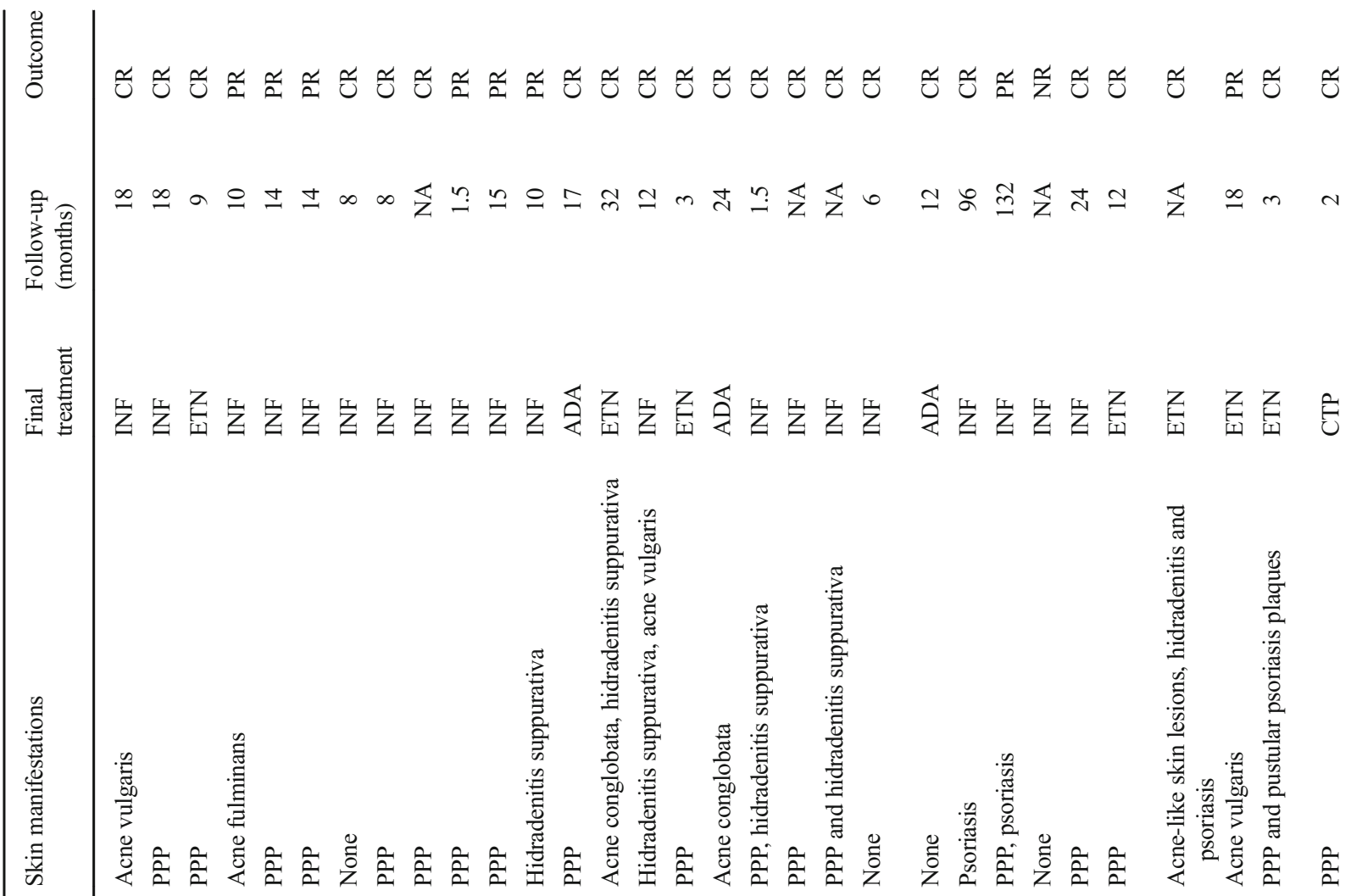

$\Sigma \Sigma$

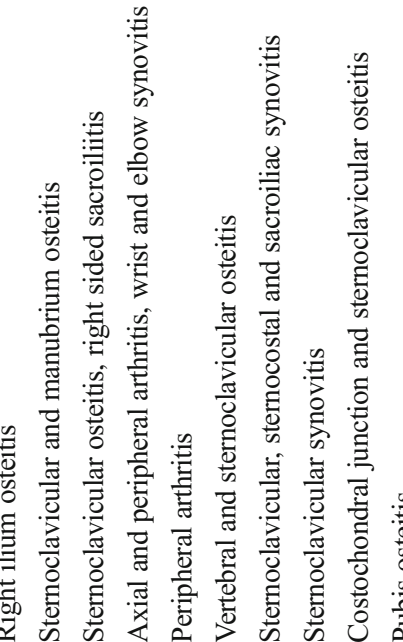

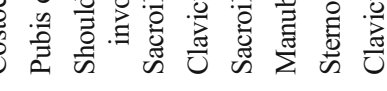

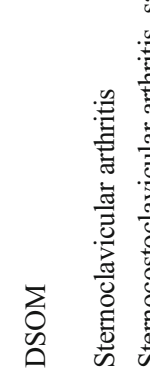

品斿

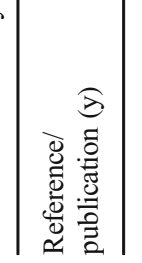

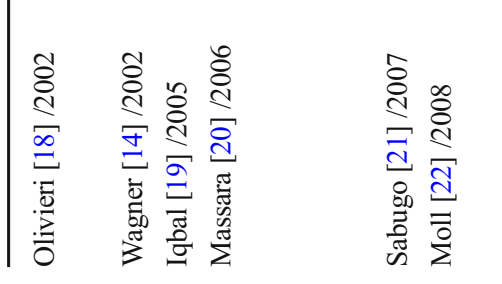

ஓे 응

离

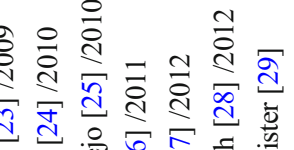

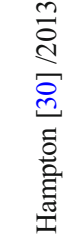

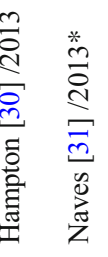

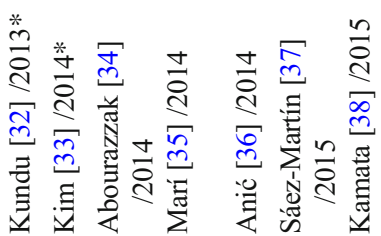




\section{Compliance with ethical standards}

Disclosures None.

Consent Both patients gave informed consent for the publication of their case report and related images.

\section{References}

1. Kahn M-F, Khan MA (1994) The SAPHO syndrome. Baillieres Clin Rheumatol 8:333-362. https://doi.org/10. 1007/978-3-540-69375-8 77

2. Li C, Cao Y, Zhang W (2018) Clinical heterogeneity of SAPHO syndrome: challenge of diagnosis. Mod Rheumatol 28:432-434. https://doi.org/10.1080/14397595.2017.1416733

3. Li C, Zuo Y, Wu N, Li L, Li F, Zhang W, Xu W, Zhao X, Jing H, Pan Q, Zhou W, Shi X, Fan Y, Wang J, Liu S, Liu Z, Zhang F, Zeng X, Chen H, Zhang S, Liu J, Qiu G, Wu Z, Dong Z, Zhang W (2016) Synovitis, acne, pustulosis, hyperostosis and osteitis syndrome: a single centre study of a cohort of 164 patients. Rheumatology (Oxford) 55:1023-1030. https://doi.org/10.1093/rheumatology/ kew015

4. Firinu D, Garcia-Larsen V, Manconi PE, Del Giacco SR (2016) SAPHO syndrome: current developments and approaches to clinical treatment. Curr Rheumatol Rep 18. https://doi.org/10.1007/ s11926-016-0583-y

5. Firinu D, Murgia G, Lorrai M, Barca M, Peralta M, Manconi P, Giacco S (2014) Biological treatments for SAPHO syndrome: an update. Inflamm Allergy Drug Targets 13:199-205. https://doi.org/ $10.2174 / 1871528113666140520100402$

6. Daoussis D, Konstantopoulou G, Kraniotis P, Sakkas L, Liossis SN (2018) Biologics in SAPHO syndrome: a systematic review. Semin Arthritis Rheum 48:618-625. https://doi.org/10.1016/j.semarthrit. 2018.04.003

7. Colina M, Pizzirani C, Khodeir M, Falzoni S, Bruschi M, Trotta F, di Virgilio F (2010) Dysregulation of P2X7receptor-inflammasome axis in SAPHO syndrome: successful treatment with anakinra. Rheumatology 49:1416-1418. https://doi.org/10.1093/ rheumatology/keq074

8. Wendling D, Prati C, Aubin F (2012) Anakinra treatment of SAPHO syndrome: short-term results of an open study. Ann Rheum Dis 71:1098-1100. https://doi.org/10.1136/annrheumdis2011-200743

9. Cornillier H, Kervarrec T, Tabareau-Delalande F, Mammou S, Jonville Bera AP, Machet L (2016) Interstitial granulomatous dermatitis occurring in a patient with SAPHO syndrome one month after starting leflunomide, and subsequently disappearing with ustekinumab. Eur J Dermatol 26:614-615. https://doi.org/10. 1684/EJD.2016.2854

10. Wendling D, Aubin F, Verhoeven F, Prati C (2017) IL-23/Th17 targeted therapies in SAPHO syndrome. A case series. Jt Bone Spine 84:733-735. https://doi.org/10.1016/j.jbspin.2017.05.016

11. Sato H, Wada Y, Hasegawa E, Nozawa Y, Nakatsue T, Ito T, Kuroda T, Saeki T, Umezu H, Suzuki Y, Nakano M, Narita I (2017) Adultonset chronic recurrent multifocal osteomyelitis with high intensity of muscles detected by magnetic resonance imaging, successfully controlled with tocilizumab. Intern Med 56:2353-2360. https://doi. org/10.2169/internalmedicine.8473-16

12. Adamo S, Nilsson J, Krebs A, Steiner U, Cozzio A, French LE, Kolios AGA (2018) Successful treatment of SAPHO syndrome with apremilast. Br J Dermatol 179:959-962. https://doi.org/10. 1111/bjd.16071 
13. Yang Q, Zhao Y, Li C, Luo Y, Hao W, Zhang W (2018) Case report: successful treatment of refractory SAPHO syndrome with the JAK inhibitor tofacitinib. Medicine (Baltimore) 97:23-26. https://doi. org/10.1097/MD.0000000000011149

14. Wagner AD, Andresen J, Jendro MC, Hülsemann JL, Zeidler H (2002) Sustained response to tumor necrosis factor $\alpha$-blocking agents in two patients with SAPHO syndrome. Arthritis Rheum 46:1965-1968. https://doi.org/10.1002/art.10539

15. Ben Abdelghani K, Dran DG, Gottenberg JE et al (2010) Tumor necrosis factor- $\alpha$ blockers in SAPHO syndrome. J Rheumatol 37: 1699-1704. https://doi.org/10.3899/jrheum.091086

16. Arias-Santiago S, Sanchez-Cano D, Callejas-Rubio JL, Fernández-Pugnaire MA, Ortego-Centeno N (2010) Adalimumab treatment for SAPHO syndrome. Acta Derm Venereol 90:301-302

17. Fujita S, Kosaka N, Mito T, Hayashi H, Morita Y (2015) Development of aseptic subcutaneous abscess after tocilizumab therapy in a patient with SAPHO syndrome complicated by amyloid A amyloidosis. Int J Rheum Dis 18:476-479. https://doi.org/ 10.1111/1756-185X.12525

18. Olivieri I, Padula A, Ciancio G, Salvarani C, Niccoli L, Cantini F (2002) Successful treatment of SAPHO syndrome with infliximab: report of two cases. Ann Rheum Dis 61:375-376

19. Iqbal M, Kolodney MS (2005) Acne fulminans with synovitisacne-pustulosis-hyperostosis-osteitis (SAPHO) syndrome treated with infliximab. J Am Acad Dermatol 52:S118-S120. https://doi. org/10.1016/j.jaad.2004.09.006

20. Massara A, Cavazzini PL, Trotta F (2006) In SAPHO syndrome anti-TNF- $\alpha$ therapy may induce persistent amelioration of osteoarticular complaints, but may exacerbate cutaneous manifestations. Rheumatology 45:730-733. https://doi.org/10.1093/ rheumatology/kei221

21. Sabugo F, Liberman C, Niedmann JP, Soto L, Cuchacovich M (2008) Infliximab can induce a prolonged clinical remission and a decrease in thyroid hormonal requirements in a patient with SAPHO syndrome and hypothyroidism. Clin Rheumatol 27:533535. https://doi.org/10.1007/s10067-007-0767-y

22. Moll C, Hernández MV, Cañete JD, Gómez-Puerta JA, Soriano A, Collado A, Sanmartí R (2008) Ilium osteitis as the main manifestation of the SAPHO syndrome: response to infliximab therapy and review of the literature. Semin Arthritis Rheum 37:299-306. https:// doi.org/10.1016/j.semarthrit.2007.08.004

23. Fruehauf J, Cierny-Modrè B, El-Shabrawi Caelen L et al (2009) Response to infliximab in SAPHO syndrome. BMJ Case Rep 2009: 1-9. https://doi.org/10.1136/bcr.10.2008.1145

24. Castellví I, Bonet M, Narváez JA, Molina-Hinojosa JC (2010) Successful treatment of SAPHO syndrome with adalimumab: a case report. Clin Rheumatol 29:1205-1207. https://doi.org/10. 1007/s10067-010-1476-5

25. Vilar-Alejo J, Dehesa L, De La Rosa-del Rey P et al (2010) SAPHO syndrome with unusual cutaneous manifestations treated successfully with etanercept. Acta Derm Venereol 90:531-532. https://doi. org/10.2340/00015555-0895

26. de Souza A, Solomon GE, Strober BE (2011) SAPHO syndrome associated with hidradenitis suppurativa successfully treated with infliximab and methotrexate. Bull NYU Hosp Jt Dis 69:185-187

27. Zhang LL, Zhao JX, Liu XY (2012) Successful treatment of SAPHO syndrome with severe spinal disorder using entercept: a case study. Rheumatol Int 32:1963-1965. https://doi.org/10.1007/ s00296-011-1916-9

28. Garcovich S, Amelia R, Magarelli N, Valenza V, Amerio P (2012) Long-term treatment of severe SAPHO syndrome with adalimumab. Am J Clin Dermatol 13:55-59. https://doi.org/10. 2165/11593250-000000000-00000
29. Burgemeister LT, Baeten DLP, Tas SW (2012) Biologics for rare inflammatory diseases: TNF blockade in the SAPHO syndrome. Neth J Med 70:444-449

30. Hampton SL, Youssef H (2013) Successful treatment of resistant SAPHO syndrome with anti-TNF therapy. BMJ Case Rep:20122014. https://doi.org/10.1136/bcr-2012-007161

31. Naves JE, Cabré E, Mañosa M, Grados D, Olivé A, Domènech E (2013) A systematic review of SAPHO syndrome and inflammatory bowel disease association. Dig Dis Sci 58:2138-2147. https:// doi.org/10.1007/s10620-013-2653-6

32. Kundu BK, Naik AK, Bhargava S, Srivastava D (2013) Diagnosing the SAPHO syndrome: a report of three cases and review of literature. Clin Rheumatol 32:1237-1243. https://doi.org/10.1007/ s10067-013-2251-1

33. Kim CH, Kadhim S, Julien C (2014) Treatment of pain in SAPHO (synovitis, acne, Pustulosis, hyperostosis, and osteitis) syndrome. PM R 6:92-95. https://doi.org/10.1016/j.pmrj. 2013.08.610

34. Abourazzak FE, Hachimi H, Kadi N, Berrada K, Tizniti S, Harzy T (2014) Etanercept in the treatment of SAPHO syndrome: which place? Eur J Rheumatol 1:125-128. https://doi.org/10.5152/ eurjrheumatol.2014.037

35. Marí A, Morla A, Melero M, Schiavone R, Rodríguez J (2014) Diffuse sclerosing osteomyelitis (DSO) of the mandible in SAPHO syndrome: a novel approach with anti-TNF therapy. Systematic review. J Cranio-Maxillofac Surg 42:1990-1996. https://doi.org/10.1016/j.jcms.2014.09.004

36. Anić B, Padjen I, Mayer M et al (2014) Clinical features of the SAPHO syndrome and their role in choosing the therapeutic approach: report of four patients and review of the literature. Acta Dermatovenerol Croat 22:180-188

37. Sáez-Martín L-C, Gómez-Castro S, Román-Curto C, PalaciosÁlvarez I, Fernández-López E (2015) Etanercept in the treatment of SAPHO syndrome. Int J Dermatol 54:e206-e208. https://doi. org/10.1111/ijd.12675

38. Kamata Y, Minota S (2015) Successful treatment of a patient with SAPHO syndrome with certolizumab pegol. Rheumatol Int 35: 1607-1608. https://doi.org/10.1007/s00296-015-3263-8

39. Cotti E, Careddu R, Schirru E, Marongiu S, Barca MP, Manconi PE, Mercuro G (2015) A case of SAPHO syndrome with endodontic implications and treatment with biologic drugs. J Endod 41:1565-1570. https://doi.org/10.1016/ j.joen.2015.04.005

40. Su YS, Chang CH (2015) SAPHO syndrome associated with acne conglobata successfully treated with etanercept. J Formos Med Assoc 114:562-564. https://doi.org/10.1016/j.jfma.2013.10.001

41. Zhang L, Gao Z (2016) Etanercept in the treatment of refractory SAPHO syndrome. Am J Clin Exp Immunol 5:62-66

42. Mateo L, Sanint J, Rodríguez Muguruza S, Martínez Morillo M, Pérez Andrés R, Domenech Puigcerver S (2017) Lesión osteolítica cervical como presentación del síndrome SAPHO. Reumatol Clin 13:44-47. https://doi.org/10.1016/j.reuma.2015.11.016

43. Anić B, Padjen I, Barešić M, Težak S (2014) The lobster sign in SAPHO syndrome: unusually extensive osteitis of the anterior chest wall partially responsive to infliximab. Rheumatol Int 34:281-282. https://doi.org/10.1007/s00296-012-2606-y

44. Cianci F, Zoli A, Gremese E, Ferraccioli G (2017) Clinical heterogeneity of SAPHO syndrome: challenging diagnose and treatment. Clin Rheumatol 36:2151-2158. https://doi.org/10.1007/s10067017-3751-1

45. Vekic DA, Woods J, Lin P, Cains GD (2018) SAPHO syndrome associated with hidradenitis suppurativa and pyoderma gangrenosum successfully treated with adalimumab and methotrexate: a case report and review of the literature. Int J Dermatol 57:10 18. https://doi.org/10.1111/ijd.13740 
46. Axmann R, Böhm C, Krönke G, Zwerina J, Smolen J, Schett G (2009) Inhibition of interleukin-6 receptor directly blocks osteoclast formation in vitro and in vivo. Arthritis Rheum 60:2747-2756. https://doi.org/10.1002/art.24781

47. Morales-Múnera C, Vilarrasa E, Puig L (2013) Efficacy of ustekinumab in refractory palmoplantar pustular psoriasis. Br J Dermatol 168:820-824

48. Kavanaugh A, Puig L, Gottlieb AB, Ritchlin C, You Y, Li S, Song M, Randazzo B, Rahman P, McInnes IB (2016) Efficacy and safety of ustekinumab in psoriatic arthritis patients with peripheral arthritis and physician-reported spondylitis: post-hoc analyses from two phase III, multicentre, double-blind, placebo-controlled studies (PSUMMIT-1/PSUMMIT-2). Ann Rheum Dis 75:1984-1988
49. Li C, Wu X, Cao Y, Zeng Y, Zhang W, Zhang S, Liu Y, Jin H, Zhang W, Li L (2019) Paradoxical skin lesions induced by anti-TNF- $\alpha$ agents in SAPHO syndrome. Clin Rheumatol 38:53-61. https:// doi.org/10.1007/s10067-018-4083-5

50. Sarzi-Puttini P, Ceribelli A, Marotto D, Batticciotto A, Atzeni F (2019) Systemic rheumatic diseases: from biological agents to small molecules. Autoimmun Rev 18:583-592. https://doi.org/10. 1016/j.autrev.2018.12.009

Publisher's note Springer Nature remains neutral with regard to jurisdictional claims in published maps and institutional affiliations. 